6 Action for Research into Multiple Sclerosis. Hyperbaric oxygen: the Dundee study. London: ARMS Education Services, 1983.

7 Fischer BH, Marks M, Reich T. Hyperbaric oxygen treatment of multiple sclerosis: randomized, placebo controlled double blind study. $N$ Engl I Med 1983;308:181-6.

8 Kelly DL, Lassiter KRL, Vongsvivut A, Smith JM. Effects of hyperbaric oxygenation and tissue oxygen studies in experimental paraplegia. $\mathcal{f}$ Neurosurg 1972;36:425-9.

9 Warren J, Sacksteder MR, Thuning CA. Oxygen immunosuppression: modification of experimental allergic encephalomyelitis in rodents. I I mmunol 1978;121:315-20.

10 Yeo JD, Lowry C, McKenzie B. Preliminary report on ten patients with spinal cord injuries treated with hyperbaric oxygen. Med f Aust 1978;ii:572-3.

treated with hyperbaric oxygen. Med $\mathcal{A}$ Aust $1978 ; \mathrm{ii}: 572-3$.
Jones RF, Unsworth IP, Marosszeky JE. Hyperbaric oxygen and acute spinal cord injuries in humans. Med J Aust 1978;ii:573-5.

12 Holbach KH, Caroli A, Wassmann H. Cerebral energy metabolism in patients with brain lesions at normo- and hyperbaric oxygen pressures. $\mathcal{I}$ Neurol 1977;217:17-30

13 Bass BH. Hyperbaric oxygen for patients with multiple sclerosis. Br Med f 1984;288: 1230.

14 Barnes MP, Bates D, Cartlidge NEF, French JM, Shaw DA. Hyperbaric oxygen and multiple sclerosis: short term results of a placebo-controlled, double blind trial. Lancet 1985;i:297-300.

$15 \mathrm{McDonald}$ WI, Halliday AM. Diagnosis and classification of multiple sclerosis. Br Med Bull 1977;33:4-8.

16 Kurtzke JF. Further notes on disability evaluation in multiple sclerosis with scale modifications. Neurology (Minneapolis) 1965:15:654-61.
17 Kurtzke JF. A proposal for a uniform minimal record of disability in multiple sclerosis. Acta Neurol Scand 1981;64, suppl 87:110-27.

18 Wiles CM, Karni Y. Muscle strength measurements in patients with peripheral neuromuscular disorders. F Neurol, Neurosurg Psychiatry 1983;46:1006-13.

19 Bloom S, Till S, Sönksen P, Smith S. Use of biothesiometer to measure individual vibration thresholds and their variation in 519 non-diabetic subjects. $\mathrm{Br} \mathrm{Med} \mathrm{f} \mathrm{1984;288:1793-5.}$

20 Jebsen RH, Taylor N, Trieschmann RB, Trotter MJ, Howard LA. An objective and standardised test of hand function. Arch Phys Med Rehabil 1969;50:311-9.

21 Kelly WG, Rannucci SR, Shaver JC. A rapid and precise method for the estimation of production rate of cortisol in man. Steroids 1968;11:429-52.

22 Massey EW, Shelton DL, Pact V, et al. Hyperbaric oxygen in multiple sclerosis: double-blind crossover study of 18 patients. Neurology 1985;35, suppl 1:104.

23 Murthy KN, Maurice PB, Wilmeth JB. Double-blind randomised study of hyperbaric oxygen (hbo) versus placebo in multiple sclerosis (ms). Neurology 1985;35, suppl 1:104.

24 Slater GE, Anderson DA, Sherman R, Ettinger MG, Haglin J, Hitchcock C. Hyperbaric oxygen and multiple sclerosis: a double blind controlled study. Neurology 1985;35, suppl 1:315.

25 Neiman J, Nilsson BY, Barr Per O, Perrins DJD. Hyperbaric oxygen in chronic progressive multiple sclerosis: visual evoked potentials and clinical effects. $\mathcal{F}$ Neurol, Neurosurg Psychiatry 1985;48:497-500

(Accepted 21 November 1985)

\title{
Placenta praevia and sex ratio at birth
}

\author{
IAN MACGILLIVRAY， DENNIS DAVEY，SEDICK ISAACS
}

\begin{abstract}
The ratio of male to female sex among infants born to 391 women with and 114079 without placenta praevia was analysed by parity. In the women without placenta praevia the sex ratio decreased significantly with increasing parity, whereas in the women with placenta praevia it increased. Overall, the sex ratio was increased among the women with placenta praevia, particularly multiparas.

An increase in the sex ratio at birth is associated with insemination early or late in the menstrual cycle, which may result in delayed development and implantation of the blastocyst; this may be a predisposing factor in placenta praevia.
\end{abstract}

\section{Introduction}

Several complications of pregnancy, including pre-eclampsia ${ }^{1}$ and premature labour, ${ }^{2}$ are associated with an increase in the ratio of male to female sex at birth. As placenta praevia is believed to be due to delayed development and implantation of the blastocyst, and as abnormalities in the development of the blastocyst are associated with alterations in the sex ratio, we investigated the sex ratio in women with placenta praevia.

\section{Subjects, method, and results}

We determined the sex ratio at delivery in 114470 singleton pregnancies (391 women with and 114079 women without placenta praevia) in the Peninsula Maternity and Neonatal Service region in Cape Town between 1976 and 1983. The women were divided into three groups according to parity (para 1, para 2 and 3, and para 4), those who were para 2 and para 3 being grouped together to ensure adequate numbers in each group (table).

\footnotetext{
Reproductive Medicine Research Unit, Department of Obstetrics and Gynaecology, University of Cape Town, 7925 Cape, South Africa IAN MACGILLIVRAY, FRCOG, professor DENNIS DAVEY, PHD, FRCOG, professor

Department of Medical Informatics, Groote Schuur Hospital, Cape Town, South Africa

SEDICK ISAACS, MSC, FSS, statistician

Correspondence to: Professor Davey.
}

In the reference population without placenta praevia the sex ratio showed a significant decrease with increasing parity $(p<0.02$, Bartholemew's test for proportions qualitatively ordered ${ }^{3}$ ). In women with placenta praevia, however, the sex ratio showed a progressive increase with increasing parity, but this trend was not significantly different from zero owing to the smaller numbers. The proportion of male births by parity in the two groups was compared by ridit analysis. ${ }^{4}$ The mean ridit for the group with placenta praevia was 0.634 (SE 0.022 ), which was significantly greater than the reference ridit value of $0.5(p<0.0001)$ with an odds ratio of $7: 4$ that multiparas with placenta praevia would have a higher proportion of male births than the reference group. Furthermore, in multiparas with four or

Ratio of male to female sex at birth among women with and without placenta praevia

\begin{tabular}{|c|c|c|c|c|c|c|}
\hline \multirow[b]{2}{*}{ Parity } & \multicolumn{3}{|c|}{ Without placenta praevia } & \multicolumn{3}{|c|}{ With placenta praevia } \\
\hline & $\begin{array}{c}\text { No of } \\
\text { male } \\
\text { infants }\end{array}$ & $\begin{array}{l}\text { No of } \\
\text { female } \\
\text { infants }\end{array}$ & $\begin{array}{l}\text { Male:female } \\
\text { ratio }\end{array}$ & $\begin{array}{c}\text { No of } \\
\text { male } \\
\text { infants }\end{array}$ & $\begin{array}{l}\text { No of } \\
\text { female } \\
\text { infants }\end{array}$ & $\begin{array}{l}\text { Male:female } \\
\text { ratio }\end{array}$ \\
\hline 1 & 22601 & 21229 & 1.065 & 34 & 31 & 1.097 \\
\hline 2 and 3 & 24172 & 23027 & 1.050 & 95 & 78 & $1 \cdot 218$ \\
\hline$\geqslant 4$ & 11671 & 11379 & 1.026 & 90 & 63 & 1.429 \\
\hline Total & 58444 & 55635 & 1.050 & 219 & 172 & $1 \cdot 273$ \\
\hline
\end{tabular}

more pregnancies the sex ratio in those with placenta praevia was 1.429 , which was significantly greater than the ratio of 1.026 in the women without placenta praevia $\left(\mathrm{p}<0.043, \mathrm{G}^{2}\right.$ test). ${ }^{5}$ The increase in the sex ratio with increasing birth order among women with placenta praevia compared with those without was thus highly significant.

\section{Discussion}

An increased ratio of male to female sex at birth among women with placenta praevia, particularly multiparas, is a new observation. Moreover, the progressive increase in sex ratio with increasing parity in placenta praevia contrasts with the decrease found in normal pregnancy.

One of the main factors influencing the sex ratio at birth is the time of insemination during the menstrual cycle, more male infants being delivered when insemination occurs two or more days before or after ovulation. ${ }^{6}$ Early and late insemination and alterations in sex ratio are also associated with an increased incidence of miscarriage. ${ }^{7}$ 
When insemination occurs early in the menstrual cycle the sperm may be over-ripe, and when fertilisation occurs later the ova may be over-ripe. Both over-ripe sperm and over-ripe ova are associated with an increased incidence of chromosomal abnormalities, blighted ova, and death of the blastocyst, and it has been suggested that in such cases female embryos may have a higher incidence of abnormalities and death. ${ }^{8}$ When early or late insemination results in fertilisation of an over-ripe ovum or by an over-ripe sperm the survival of male embryos may thus be relatively increased, resulting in an increased male to female sex ratio at birth. Similarly, the development of the embryo from an over-ripe sperm or ova may be impaired, resulting in delayed and low implantation of the embryo in the uterus and hence placenta praevia.

Placenta praevia may thus be due to delayed development and implantation of the blastocyst resulting from early or late insemination, which is associated with an increase in the male to female sex ratio. The progressive increase in the sex ratio with increasing parity in women with placenta praevia is difficult to explain unless increasing parity is in some way associated with an increase in the incidence of fertilisation of over-ripe ova or by over-ripe sperms. The significant increase in the sex ratio nevertheless suggests that early or late insemination and impaired development of the embryo may be a predisposing factor in placenta praevia.

\section{References}

1 MacGillivray I. Eclampsia, the hypertensive disease of pregnancy. London, Philadelphia, Toronto: B Saunders, 1983.

Hall M, Carr-Hill $\mathrm{R}$. Impact of sex ratio on onset and management of labour. $\mathrm{Br} \mathrm{Med}$ 1982;285:401-3.

3 Bartholemew DJ. On Chassen's test for order. Biometrics 1963;19:188-91.

4 Kantor $S$, Winkelstein W, Ibrahim MA. A note on the interpretation of the ridit as a quantile rank. Am $\mathcal{Y}$ Epidemiol 1968;87:609-15.

5 Payne C. The log-linear model for contingency table analysis. In: Payne C, O'Muircheartaigh CA, eds. Model fiting. London: Wiley, 1977.

6 Harlap S. Gender of infants conceived on different days of the menstrual cycle. N Engl 7 Med 979;300:1445-8.

7 Guerrero R, Rojas OI. Spontaneous abortion and aging of human ova and spermatozoa. $N$ Engl $\mathcal{J}$ Med 1975;293:573-5.

8 Witschi E. Teratogenic effects of overripeness of the egg. In: Fraser FC, McKusick VA, Robinson R, eds. Congenital malformations. Amsterdam: Excerpta Medica, 1970. (International Congress Series No 204.)

(Accepted 2 December 1985)

\title{
An epidemiological study of the immunogenetic aetiology of pre-eclampsia
}

\author{
BETH W ALDERMAN, RHODA S SPERLING, JANET R DALING
}

\begin{abstract}
A population based case-control study of the association between dissimilar race of parents and risk of pre-eclampsia was undertaken. Data on singleton births in Washington State in 1981 were available for analysis from birth certificates. All mothers recorded as having pre-eclampsia and a sample of mothers who did not have pre-eclampsia were eligible for comparison with regard to racial dissimilarity between parents. Women with previously diagnosed cardiovascular disease and diabetes were excluded. After the confounding effects of maternal parity and race had been controlled for, racial dissimilarity of parents was associated with a 1.9-fold increased risk of pre-eclampsia (95\% confidence interval $=1 \cdot 3-2 \cdot 8$; number of cases $=973$, of controls $=$ 1480).
\end{abstract}

This finding supports the theory that genetic dissimilarity of father and mother has a role in pre-eclampsia and is consistent with an immunogenetic aetiology.

\footnotetext{
Department of Preventive Medicine and Biometrics, University of Colorado Medical School, Denver, Colorado
}

BETH W ALDERMAN, MD, MPH, assistant professor

Department of Obstetrics, Gynecology, and Reproductive Medicine, Mount Sinai Hospital, New York

RHODA S SPERLING, MD, clinical instructor

Department of Epidemiology, University of Washington School of Public Health, Seattle, Washington State

JANET R DALING, PHD, associate professor

Correspondence to: Dr Beth W Alderman, Department of Preventive Medicine and Biometrics, University of Colorado Health Sciences Center, Campus Box C245, 4200 East Ninth Avenue, Denver, Colorado 80262.

\section{Introduction}

Previous studies have linked paternal factors with pre-eclampsia. ${ }^{12}$ Several reports have indicated that change of paternity is associated with an increased occurrence of pre-eclampsia among multiparous women, ${ }^{3-5}$ while others have suggested that exposure to paternal spermatic antigens may protect against pre-eclampsia. ${ }^{6}$ Such observations support the theory that pre-eclampsia may represent a disorder in the maternal immune response to paternally inherited antigens expressed by the fetus.

Some investigators believe that paternal antigens may increase the risk of pre-eclampsia through genetic dissimilarity from the mother, which results in "immunological" incompatibility between fetus and mother. ${ }^{7}$ This theory is supported by a large epidemiological study of a highly consanguineous population, which found that paternal unrelatedness to the mother was associated with an increased risk of pre-eclampsia. ${ }^{8}$ Other investigators, however, believe that the depression of the maternal immune response in pre-eclampsia may result from inadequate stimulation of the immune response owing to genetic similarity of the father and mother. ${ }^{9}$

We designed a population based case-control study to re-examine the relation between pre-eclampsia and a global measure of genetic dissimilarity of mother and father. Dissimilar race of parents, rather than lack of consanguinity, was used as the indicator of genetic dissimilarity.

\section{Methods}

Birth certificates for all single births that occurred in Washington State in 1981 were used to identify subjects and provide data for analysis. All women who were recorded as having pre-eclampsia on the birth certificate were eligible for inclusion in the study. According to protocol, the birth certificate is completed within two days of birth by a nurse or doctor who was present at the birth or by a member of staff at the hospital who has been trained by the state health department. If the attending doctor has diagnosed pre-eclampsia a box labelled pre-eclampsia is to be ticked on the certificate. This protocol is followed closely, as shown by a recent study, which found that after the 